TITLE:

\title{
Visible to near infrared conversion in Ce3+-Yb3+ Co-doped YAG ceramics
}

\section{AUTHOR(S):}

Ueda, Jumpei; Tanabe, Setsuhisa

\section{CITATION:}

Ueda, Jumpei ...[et al]. Visible to near infrared conversion in Ce3+-Yb3+ Co-doped YAG ceramics. Journal of Applied Physics 2009, 106(4):

043101

ISSUE DATE:

2009-08-17

URL:

http://hdl.handle.net/2433/150457

RIGHT:

Copyright c 2009, American Institute of Physics 


\section{AIP Appilied Pysics}

\section{Visible to near infrared conversion in Ce3+-Yb3+Co-doped YAG ceramics}

Jumpei Ueda and Setsuhisa Tanabe

Citation: J. Appl. Phys. 106, 043101 (2009); doi: 10.1063/1.3194310

View online: http://dx.doi.org/10.1063/1.3194310

View Table of Contents: http://jap.aip.org/resource/1/JAPIAU/v106/i4

Published by the American Institute of Physics.

\section{Related Articles}

Microcavity effects in SiGe/Si heterogeneous nanostructures prepared by electrochemical anodization of $\mathrm{SiGe} / \mathrm{Si}$ multiple quantum wells

J. Appl. Phys. 110, 103101 (2011)

Microstructure, optical property, and electronic band structure of cuprous oxide thin films

J. Appl. Phys. 110, 103503 (2011)

Suppression of luminescence quenching at the nanometer scale in Gd2O3 doped with Eu3+ or Tb3+: Systematic comparison between nanometric and macroscopic samples of life-time, quantum yield, radiative and non-

radiative decay rates

J. Appl. Phys. 110, 094317 (2011)

Influence of local atomic configuration in AIGdN phosphor thin films on deep ultra-violet luminescence intensity J. Appl. Phys. 110, 093108 (2011)

Comparative investigation on the $2.7 \mathrm{~m}$ emission in Er3+/Ho3+ codoped fluorophosphate glass

J. Appl. Phys. 110, 093106 (2011)

\section{Additional information on J. Appl. Phys.}

Journal Homepage: http://jap.aip.org/

Journal Information: http://jap.aip.org/about/about_the_journal

Top downloads: http://jap.aip.org/features/most_downloaded

Information for Authors: http://jap.aip.org/authors

\section{ADVERTISEMENT}

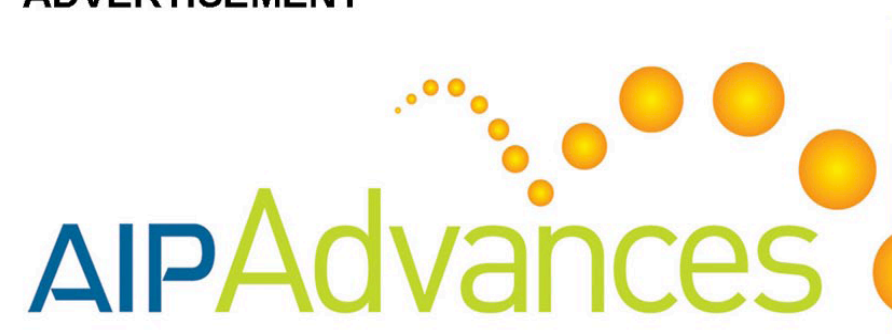

Submit Now

\section{Explore AIP's new \\ open-access journal}

Article-level metrics now available

Join the conversation!

Rate \& comment on articles 


\title{
Visible to near infrared conversion in $\mathrm{Ce}^{3+}-\mathrm{Yb}^{3+}$ Co-doped YAG ceramics
}

\author{
Jumpei Ueda ${ }^{\text {a) }}$ and Setsuhisa Tanabe \\ Graduate School of Human and Environmental Studies, Kyoto University, Yoshida-nihonmatsu-cho \\ Sakyo-ku, Kyoto 606-8501, Japan
}

(Received 25 June 2009; accepted 7 July 2009; published online 17 August 2009)

\begin{abstract}
In $\mathrm{Ce}^{3+}-\mathrm{Yb}^{3+}$ co-doped $\mathrm{Y}_{3} \mathrm{Al}_{5} \mathrm{O}_{12}$ (YAG) ceramics, possibility of quantum cutting mechanism converting one visible photon into two NIR photons with optimum quantum efficiency approaching $200 \%$ have been investigated. In this material, $\mathrm{Yb}^{3+}$ emissions due to the ${ }^{2} F_{5 / 2}{ }^{2} F_{7 / 2}$ in the range of $1 \mu \mathrm{m}$ were observed upon the excitation of $5 d$ level of $\mathrm{Ce}^{3+}$. In addition, excitation spectra of $\mathrm{Yb}^{3+}$ emission corresponded to that of $\mathrm{Ce}^{3+}$ emission completely. Lifetime of the $5 d$ level of $\mathrm{Ce}^{3+}$ decreased with increasing $\mathrm{Yb}^{3+}$ content. These results indicate the energy transfer (ET) from the $5 d$ levels of $\mathrm{Ce}^{3+}$ to the ${ }^{5} F_{5 / 2}$ level of $\mathrm{Yb}^{3+}$. In $\left(\mathrm{Y}_{0.945} \mathrm{Ce}_{0.005} \mathrm{Yb}_{0.05}\right){ }_{3} \mathrm{Al}_{5} \mathrm{O}_{12}$ sample, the directly measured quantum yield (QY) of $\mathrm{Yb}^{3+}$ emission upon the excitation of $5 d$ level of $\mathrm{Ce}^{3+}$ was about $12 \%$ and lower than QY (96\%) that estimated from the ET efficiency which was calculated with the measured lifetime of $\mathrm{Ce}^{3+}$. (C) 2009 American Institute of Physics. [DOI: 10.1063/1.3194310]
\end{abstract}

\section{INTRODUCTION}

Luminescent materials doped with rare earth ions are used for many devices such as optical amplifiers in telecommunication, phosphors for white light emitting diodes (LEDs), displays, and so on. Recently, they also have attracted a great interest for photovoltaic applications to improve solar cell efficiency by modifying solar spectrum. ${ }^{1}$ Figure 1 shows the solar spectrum and the spectral response of crystalline silicon solar cell. Crystal silicon $(c-\mathrm{Si})$ solar cells most effectively convert photons of energy close to the semiconductor band gap. The mismatch between the incident solar spectrum and the spectral response of solar cells is one of the main reasons to limit the cell efficiency. The efficiency limit of the $c$-Si have been estimated to be $29 \%$ by Shockley and Queisser. ${ }^{2}$ However, this limit is estimated to be improved up to $38.4 \%$ by modifying the solar spectrum by a quantum cutting (downconverting) phosphor which converts one photon of high energy into two photons of lower energy. $^{3}$

The phenomenon such as the quantum cutting or the downconversion of rare earth ions have been investigated since Dexter ${ }^{4}$ reported the possibility of a luminescent quantum yield greater than unity in 1957. In the past, the quantum cutting from a vacuum ultraviolet photon to visible photons for $\mathrm{Pr}^{3+},{ }^{5,6} \mathrm{Gd}^{3+}, \mathrm{Gd}^{3+}-\mathrm{Eu}^{3+8}$, and $\mathrm{Er}^{3+}-\mathrm{Tb}^{3+9}$ had been studied. Recently, a new quantum cutting phenomenon from visible photon shorter than $500 \mathrm{~nm}$ to two infrared photons for $\mathrm{Tb}^{3+}-\mathrm{Yb}^{3+},{ }^{10-13} \mathrm{Pr}^{3+}-\mathrm{Yb}^{3+},{ }^{14}$ and $\mathrm{Tm}^{3+}-\mathrm{Yb}^{3+15}$ has been reported. The $\mathrm{Yb}^{3+}$ ion is suitable as an acceptor and emitter because luminescent quantum efficiency of $\mathrm{Yb}^{3+}$ is close to $100 \%$ and the energy of the only excited level of $\mathrm{Yb}^{3+}(\sim 1.2 \mathrm{eV})$ is roughly in accordance with the band gap of $\mathrm{Si}(\sim 1.1 \mathrm{eV})$. However, absorption transitions of $\mathrm{Pr}^{3+}$, $\mathrm{Tb}^{3+}$, and $\mathrm{Tm}^{3+}$ as a donor are due to forbidden $f-f$ transitions. Therefore, the absorption linewidth and cross sections are not so wide and large, respectively. On the other hand,

${ }^{\text {a)} E l e c t r o n i c ~ m a i l: ~ j . u e d a @ a t 3 . e c s . k y o t o-u . a c . j p . ~}$ optical transitions of $\mathrm{Ce}^{3+}$ in the $\mathrm{UV}$ to visible regions are due to allowed $f$ - $d$ transitions. As a result the absorption linewidth and cross sections are wide and large, respectively. In addition, the $\mathrm{Ce}^{3+}$-doped $\mathrm{Y}_{3} \mathrm{Al}_{5} \mathrm{O}_{12}$ (YAG), used as a phosphor for white LED, has broad absorption bands in the range of 300-500 $\mathrm{nm}$ due to strong ligand field and high luminescent quantum efficiency. ${ }^{16,17}$ Therefore, the $\mathrm{Ce}^{3+}$ ions in the YAG can be suitable as an excellent sensitizing donor for down conversion materials of $\mathrm{Si}$ solar cells.

In this study, $\mathrm{Ce}^{3+}-\mathrm{Yb}^{3+}$-codoped YAG ceramics were prepared and the energy transfer (ET) including down conversion mechanism in $\mathrm{Ce}^{3+}-\mathrm{Yb}^{3+}$ codoped $\mathrm{YAG}$ ceramics have been evaluated by the photoluminescence (PL), the photoluminescence excitation (PLE), the lifetime and the quantum yield (QY), which was measured directly using an integrating sphere.

\section{EXPERIMENT}

Polycrystalline YAG ceramics with composition of $\left(\mathrm{Y}_{0.995-x} \mathrm{Ce}_{0.005} \mathrm{Yb}_{x}\right){ }_{3} \mathrm{Al}_{5} \mathrm{O}_{12}(x=0,0.005,0.02,0.05$, and

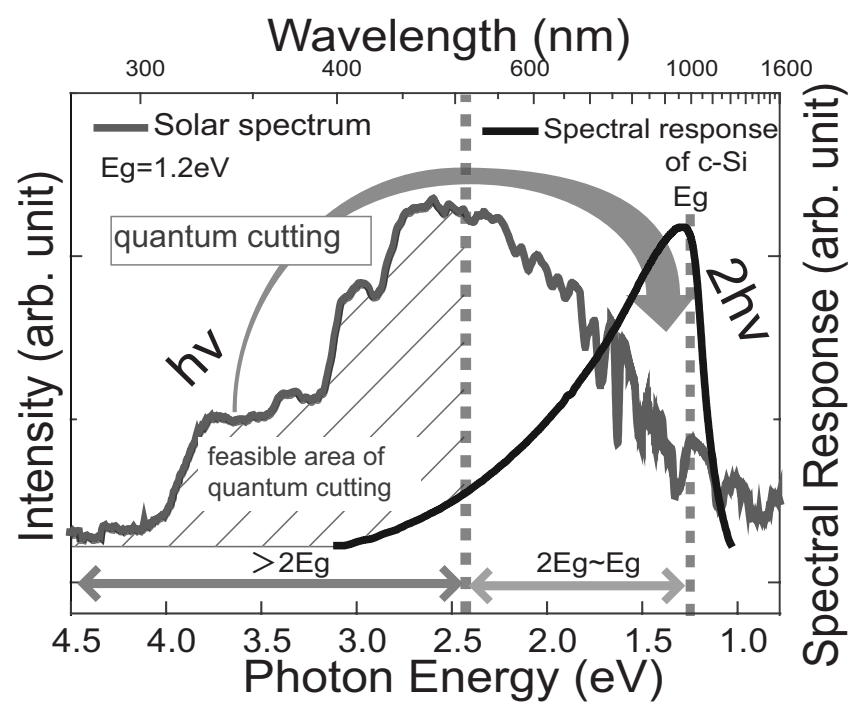

FIG. 1. Solar spectrum and spectral response of $c$-Si. 
0.1) were prepared by using reagent grade $\mathrm{Y}_{2} \mathrm{O}_{3}(99.99 \%)$, $\mathrm{Al}_{2} \mathrm{O}_{3}$ (99.99\%), $\mathrm{CeO}_{2}$ (99.99\%), and $\mathrm{Yb}_{2} \mathrm{O}_{3}(99.99 \%)$ as starting materials. The powders were mixed well with tetraethyl orthosilicate $(0.5 \mathrm{wt} \%)$ in an alumina mortar to facilitate solid state reaction, pressed into a pellet of $20 \mathrm{~mm}$ diameter and sintered at $1600{ }^{\circ} \mathrm{C}$ for $6 \mathrm{~h}$. The first obtained polycrystalline pellets were crushed, pressed and sintered again to obtain complete single phase of YAG. The crystal phases of obtained samples were identified by an X-ray diffraction (XRD) measurement (Shimadzu, XRD6000). For the PL spectra, samples were excited by using $450 \mathrm{~nm}$ light that was obtained by combining a band pass filter and a $\mathrm{Xe}$ lamp (Asahi Spectra Co., Ltd., MAX-302). The luminescence spectra were measured with a monochromator (Nikon, G250) and a Si photodiode (Electro-Optical System Inc., S-025-H). The obtained PL spectra were calibrated by a standard halogen lamp (Labsphere, OGL-600). In the PLE spectra measurement monitoring near infrared luminescence, the luminescence was detected by combining an $850 \mathrm{~nm}$ short cut filter and an InGaAs (Electro-Optical System Inc., IGA010-H) photodiode. Samples were excited by monochromatic light obtained by combining the Xe lamp (350-800 $\mathrm{nm}$ ) and the monochromator. For the PLE spectra monitoring visible luminescence, a $550 \mathrm{~nm}$ bandpass filter and the $\mathrm{Si}$ photodiode were used. For the luminescent decay measurement, samples were excited by using a $466 \mathrm{~nm}$ dye (Exciton, LD466) laser pumped with a nitrogen laser pulse excitation. The decay curves of fluorescence at 550 and $1030 \mathrm{~nm}$ were detected by a high-speed silicon detector (Thorlabs, Inc., DET110) and averaged on a digital oscilloscope (Yokogawa, DL1620). For the QY of emission upon the excitation of $\mathrm{Ce}^{3+}: 5 d$ level, the PL spectra were measured under the 440 nm LD excitation (Nichica, NDHB510APA) by using an integrating sphere (Labsphere) which was connected to a charge coupled device (CCD) detector of visible range (Ocean Optics, USB2000) and a CCD detector of infrared range (Ocean Optics, USB2000+) with an optical bifurcated fiber of $400 \mu \mathrm{m}$ core. The obtained PL spectra were calibrated by using the standard halogen lamp and an auxiliary lamp (Labsphere, AUX-30), and then the total radiant flux and photon distribution were obtained. The QY was evaluated as the ratio of the emission photon number to the absorption photon number. For the QY of emission upon the excitation of $\mathrm{Yb}^{3+}$, the $935 \mathrm{~nm}$ laser diode (LD) (Qphotonics, QLD-945-100S) was used as excitation.

\section{RESULTS}

\section{A. YAG samples}

The XRD patterns of obtained samples are shown in Fig. 2. The XRD patterns of all samples almost corresponded to that of the YAG. ${ }^{18}$ The XRD peaks were slightly shifted to higher angle $(2 \theta)$ with increasing $\mathrm{Yb}^{3+}$ content (inset in Fig. 2).

\section{B. Optical property of $\mathrm{Ce}^{3+}$ and $\mathrm{Yb}^{3+}$ in YAG 1. Photoluminescence and photoluminescence} excitation

Figure 3 shows the PL spectrum by $450 \mathrm{~nm}$ excitation and the PLE spectra monitoring 550 and $1030 \mathrm{~nm}$ of the

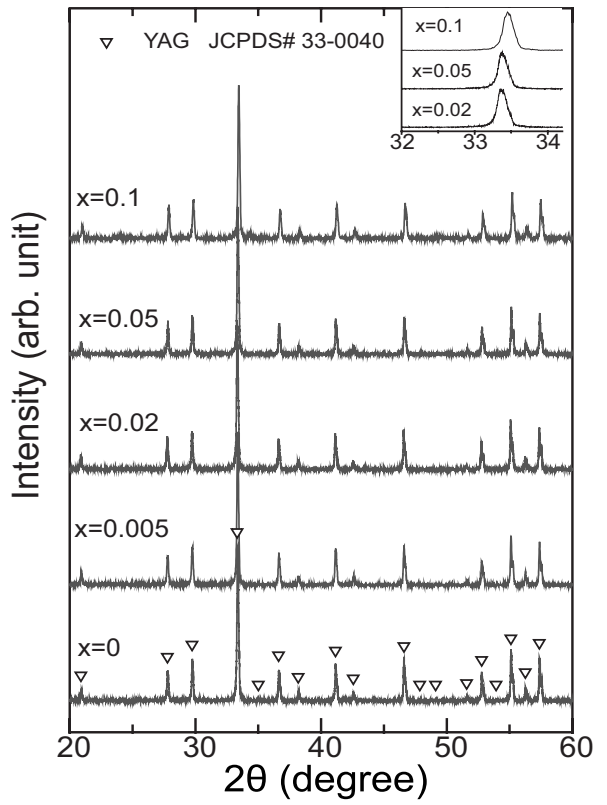

FIG. 2. XRD patterns of $\mathrm{Ce}^{3+}-\mathrm{Yb}^{3+}$ codoped YAG with different $\mathrm{Yb}^{3+}$ contents. (Inset is extend figure of main peak in some samples).

sample with $x=0.05$ composition. The emission bands peaked at $550 \mathrm{~nm} \quad\left(\mathrm{Ce}^{3+}: 5 d-4 f\right)$ and $1030 \mathrm{~nm}$ $\left(\mathrm{Yb}^{3+}:{ }^{2} F_{5 / 2^{-}}{ }^{2} F_{7 / 2}\right)$ were observed by exciting the $5 d$ level of $\mathrm{Ce}^{3+}$ with $450 \mathrm{~nm}$ light. For the PLE spectrum monitoring $550 \mathrm{~nm}$, the broad excitation bands were located at 330 and $450 \mathrm{~nm}$. For the PLE spectrum monitoring $1030 \mathrm{~nm}$, a broad excitation band located at $450 \mathrm{~nm}$ was also observed. These two PLE spectra were consistent between 400 and $500 \mathrm{~nm}$.

\section{Decay curves}

Figure 4 shows the decay curves of $\mathrm{Ce}^{3+}$ emission at 540 $\mathrm{nm}$ under the $466 \mathrm{~nm}$ dye laser. Each decay curve was fitted by the following single exponential function:

$$
I=I_{0} \exp \left(-t / \tau_{\text {decay }}\right) .
$$

It can be seen that the decay times were decreased with increasing $\mathrm{Yb}^{3+}$ content. Figure 5 shows the decay curves of emission at $1030 \mathrm{~nm}$ due to $\mathrm{Yb}^{3+}$ transition $\left({ }^{2} F_{5 / 2} \rightarrow{ }^{2} F_{7 / 2}\right)$. In this measurement, both rise and decay components were observed. Each decay curve was fitted by the following double exponential function:

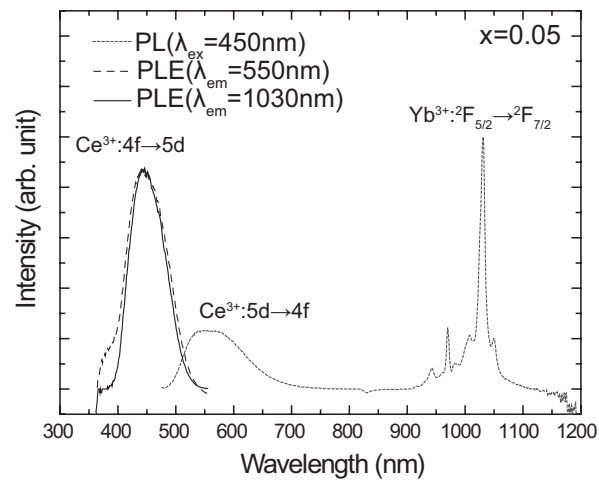

FIG. 3. PL spectrum by the $450 \mathrm{~nm}$ LD excitation and PLE spectra monitored at 550 and $1030 \mathrm{~nm}$ in $\mathrm{Ce}^{3+}-\mathrm{Yb}^{3+}$ codoped YAG. 


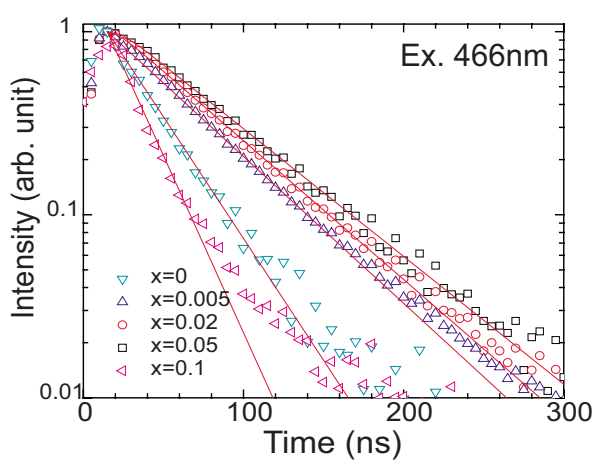

FIG. 4. (Color online) Single logarithmic chart of decay curves, which monitored emission from $5 d$ level of $\mathrm{Ce}^{3+}$ by $466 \mathrm{~nm}$ excitation, in samples with different $\mathrm{Yb}^{3+}$ contents.

$$
I=I_{0}\left\{\exp \left(-t / \tau_{\text {decay }}\right)-\exp \left(-t / \tau_{\text {rise }}\right)\right\}
$$

\section{TOTAL RADIANT FLUX}

Figure 6 shows the total radiant flux spectra of some samples by $440 \mathrm{~nm}$ LD excitation. In the sample with $x=0$ composition, the intense emission at around $540 \mathrm{~nm}$ was observed, while no emission at around $1030 \mathrm{~nm}$ was observed. The intensity of emission at around $540 \mathrm{~nm}$ was decreased with increasing $\mathrm{Yb}^{3+}$ content, while that at around $1030 \mathrm{~nm}$ was increased with increasing $\mathrm{Yb}^{3+}$ content until $x=5$ composition. Figure 7 shows the radiant flux spectra of samples in the range of near infrared by $935 \mathrm{~nm}$ LD excitation.

\section{DISCUSSIONS}

\section{A. YAG samples}

From the obtained XRD peaks, the lattice constant, $a$, of the YAG ceramics was estimated by the following equation that combined the Bragg's equation with a relation of cubic lattice constant with the Miller's indices:

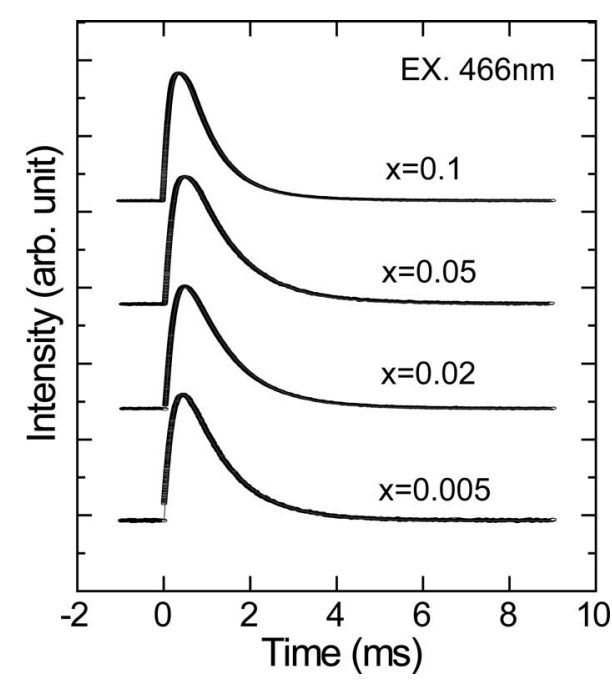

FIG. 5. $\mathrm{Yb}^{3+}$ content variation of decay curve, which monitored emission from the ${ }^{2} F_{5 / 2}$ of $\mathrm{Yb}^{3+}$ by $466 \mathrm{~nm}$ excitation.

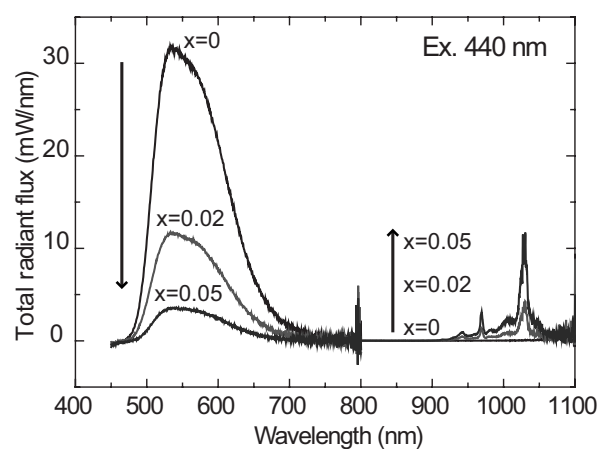

FIG. 6. $\mathrm{Yb}^{3+}$ content variation total radiant flux spectra by $440 \mathrm{~nm}$ excitation.

$$
a=\frac{\lambda \sqrt{h^{2}+k^{2}+l^{2}}}{2 \sin \theta}
$$

where $\lambda$ is the wavelength of $\mathrm{Cu} K_{\alpha}$ radiation, $(h, k, l)$ is the Miller's indices and $\theta$ is the angle of diffraction peak. Figure 8 shows the calculated lattice constant and reference crystal of $\mathrm{Y}_{3} \mathrm{Al}_{5} \mathrm{O}_{12}: \mathrm{YAG}^{18}$ and $\mathrm{Yb}_{3} \mathrm{Al}_{5} \mathrm{O}_{12}$ : $\mathrm{YBAG}^{19}$ The lattice constant of obtained YAG were decreased with increasing $\mathrm{Yb}^{3+}$ content following Vegard's law. Therefore, it was confirmed that $\mathrm{Yb}^{3+}$ ions were incorporated into YAG crystal.

\section{B. Optical property of $\mathrm{Ce}^{3+}$ and $\mathrm{Yb}^{3+}$ in YAG 1. Energy transfer from $\mathrm{Ce}^{3+}$ to $\mathrm{Yb}^{3+}$}

Results of the PL and PLE spectra of the sample with $x=0.05$ composition in Fig. 3 indicated evidence of energy transfer from the $5 d$ levels of $\mathrm{Ce}^{3+}$ to the ${ }^{2} F_{5 / 2}$ level of $\mathrm{Yb}^{3+}$. The excitation bands of $\mathrm{Ce}^{3+}$ correspond to the peak energy of solar spectrum, which is in a range of low spectral response of $c$-Si. In addition, the emission band peaked at 1030 $\mathrm{nm}$ corresponds to a range of high spectral response. Therefore, the ET from $\mathrm{Ce}^{3+}$ to $\mathrm{Yb}^{3+}$ in YAG ceramics is suitable for solar spectrum convertor from viewpoint spectral characteristics of the PL and the PLE. From decreasing of lifetime of $\mathrm{Ce}^{3+}: 5 d$ level with increasing $\mathrm{Yb}^{3+}$ content, it is considered that energy transfer from $\mathrm{Ce}^{3+}$ to $\mathrm{Yb}^{3+}$ occurred. The total decay rate $\left(W_{\text {tot }}\right)$ of $5 d$ levels in $\mathrm{Ce}^{3+}$ single doped YAG sample is given by

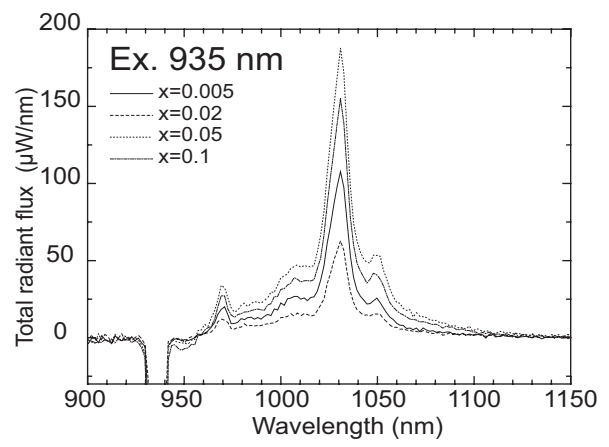

FIG. 7. $\mathrm{Yb}^{3+}$ content variation total radiant flux spectra by $935 \mathrm{~nm}$ excitation. 


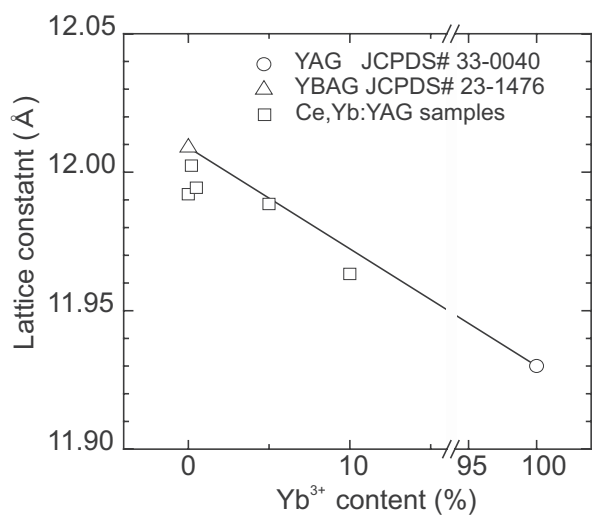

FIG. 8. $\mathrm{Yb}^{3+}$ content dependence of lattice constant of $\mathrm{Ce}^{3+}-\mathrm{Yb}^{3+}$ codoped YAG. Solid line is lattice constant estimated from Vegard's law.

$$
W_{\mathrm{tot}}=A+W_{\mathrm{MP}}=\tau_{\mathrm{Ce}}^{-1},
$$

where $A$ is the radiative rate, $W_{\mathrm{MP}}$ is the multiphonon relaxation rate, and $\tau_{\mathrm{Ce}}$ is the lifetime of $5 d$ level in $\mathrm{Ce}^{3+}$ single doped YAG. In $\mathrm{Ce}^{3+}, \mathrm{Yb}^{3+}$-codoped $\mathrm{YAG}$, the extra decay pathway from $5 d$ level of $\mathrm{Ce}^{3+}$ to ${ }^{2} F_{5 / 2}$ level of $\mathrm{Yb}^{3+}$ was generated. Therefore, the total decay rate is given by

$$
W_{\mathrm{tot}}=A+W_{\mathrm{MP}}+W_{\mathrm{ET}}=\tau_{\mathrm{Ce}, \mathrm{Yb}}^{-1}
$$

where $W_{\mathrm{ET}}$ is the energy transfer rate and $\tau_{\mathrm{Ce}, \mathrm{Yb}}$ is the lifetime of $5 d$ level in $\mathrm{Ce}^{3+}-\mathrm{Yb}^{3+}$ codoped YAG. Therefore the energy transfer efficiency is given by

$$
\eta_{\mathrm{ET}}=\frac{W_{\mathrm{ET}}}{A+W_{\mathrm{MP}}+W_{\mathrm{ET}}}=1-\frac{\tau_{\mathrm{Ce}, \mathrm{Yb}}}{\tau_{\mathrm{Ce}}} .
$$

Figure 9 shows the $\mathrm{Yb}^{3+}$ content dependences of lifetime for the $5 d$ level of $\mathrm{Ce}^{3+}$ and the ET efficiency from the $5 d$ level of $\mathrm{Ce}^{3+}$ to the ${ }^{2} F_{5 / 2}$ of $\mathrm{Yb}^{3+}$. The lifetime decreased with increasing $\mathrm{Yb}^{3+}$ content, the ET efficiency increased with increasing $\mathrm{Yb}^{3+}$ content. The ET efficiency exceeded about $50 \%$ above $x=0.05$ composition. Therefore, the quantum yield of $\mathrm{Yb}^{3+}$ will be over $100 \%$ if ideal quantum cutting occurred as the equation given by

$$
\mathrm{QY}=2 \eta_{\mathrm{Yb}} \eta_{\mathrm{ET}}
$$

where $\eta_{\mathrm{Yb}}$ is the emission quantum efficiency of $\mathrm{Yb}^{3+}$, usually about $100 \%$ because of low multiphonon relaxation rate due to large energy gap to the next lower level, the ground

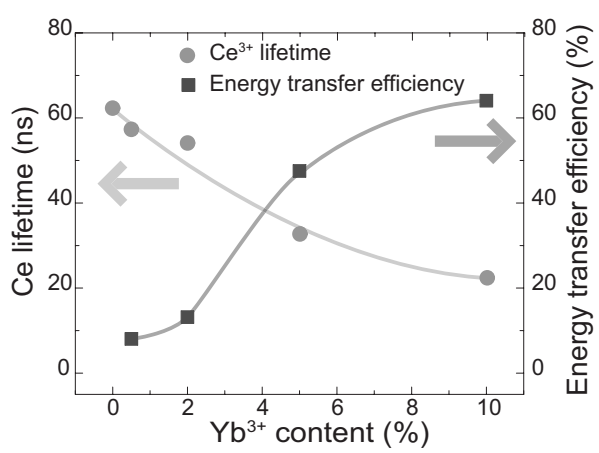

FIG. 9. $\mathrm{Yb}^{3+}$ content dependence of lifetime at $5 d$ level of $\mathrm{Ce}^{3+}$ and energy transfer efficiency from $\mathrm{Ce}^{3+}$ to $\mathrm{Yb}^{3+}$.

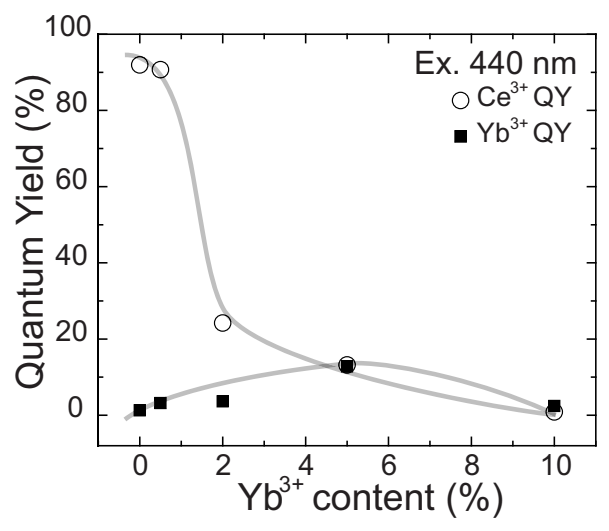

FIG. 10. $\mathrm{Yb}^{3+}$ content dependence of quantum yield of $\mathrm{Ce}^{3+}$ emission and $\mathrm{Yb}^{3+}$ emission by $440 \mathrm{~nm}$ excitation.

state. In the sample with $x=0.05$ composition, the QY was estimated high value $(96 \%)$.

\section{TOTAL RADIANT FLUX}

From the total radiant flux spectrum by $440 \mathrm{~nm}$ LD excitation, the photon distribution spectrum can be obtained. Therefore the emission and absorption photon number was estimated, and then the quantum efficiency was calculated. Figure 10 shows the $\mathrm{Yb}^{3+}$ content dependences of the QY of $\mathrm{Ce}^{3+}$ emission at around $550 \mathrm{~nm}$ and that of $\mathrm{Yb}^{3+}$ emission at around $1030 \mathrm{~nm}$. The QY of $\mathrm{Ce}^{3+}$ emission decreased and that of $\mathrm{Yb}^{3+}$ emission increased with increasing $\mathrm{Yb}^{3+}$ content. The maximum value of $\mathrm{QY}$ of $\mathrm{Yb}^{3+}$ was $12.8 \%$ in the $x=0.05$ sample and lower than that estimated from the ET efficiency, which was calculated with the measured lifetime of $\mathrm{Ce}^{3+}: 5 d$ level. It is considered that other nonradiative processes existed. From the radiant flux spectrum by $935 \mathrm{~nm}$ LD excitation, the QY of $\mathrm{Yb}^{3+}$ was calculated. Figure 11 shows the $\mathrm{Yb}^{3+}$ content dependence of QY of the $\mathrm{Yb}^{3+}$ emission by $935 \mathrm{~nm}$ LD excitation. At least the QY indicated higher value than $80 \%$ until $x=0.05$. Therefore it is considered that the nonradiative processes are not due to concentration quenching of $\mathrm{Yb}^{3+}$.

\section{ENERGY TRANSFER MECHANISM}

Figure 12 shows the $\mathrm{Yb}^{3+}$ content dependence of rise and decay time of the $\mathrm{Yb}^{3+}$ emission by $466 \mathrm{~nm}$ excitation.

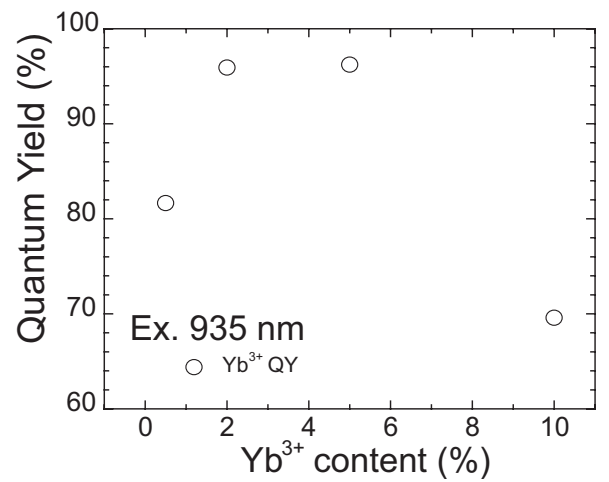

FIG. 11. $\mathrm{Yb}^{3+}$ content dependence of quantum yield of $\mathrm{Yb}^{3+}$ emission and by $935 \mathrm{~nm}$ excitation. 


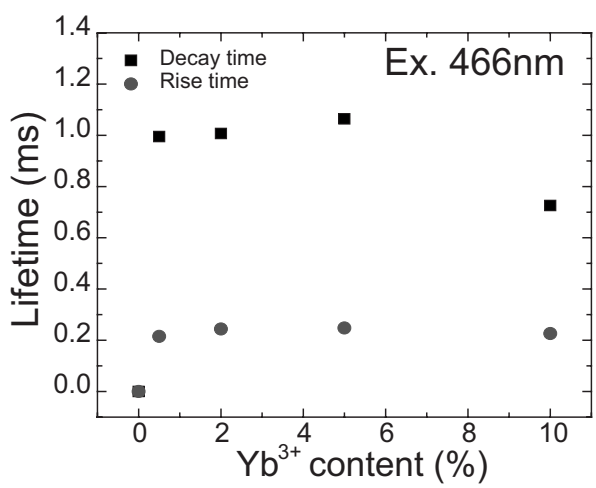

FIG. 12. $\mathrm{Yb}^{3+}$ content dependence of lifetime at ${ }^{2} F_{5 / 2}$ of $\mathrm{Yb}^{3+}$ by $466 \mathrm{~nm}$ excitation.

The decay time decreased at $x=0.1$ composition. It is considered that concentration quenching of $\mathrm{Yb}^{3+}$ occurred. The rise time should correspond to relaxation time from the $5 d$ levels of $\mathrm{Ce}^{3+}$ to the ${ }^{2} F_{7 / 2}$ of $\mathrm{Yb}^{3+}$. However, the rise time was about $0.2 \mathrm{~ms}$ in all the samples and longer than lifetime $(\sim 100 \mathrm{~ns})$ of $\mathrm{Ce}^{3+}: 5 d$ level estimated from measurement of decay curve by $440 \mathrm{~nm}$ LD excitation. These results indicated that the energy transfer from the $5 d$ level of $\mathrm{Ce}^{3+}$ to the ${ }^{2} F_{5 / 2}$ of $\mathrm{Yb}^{3+}$ is not through direct process. It is considered that the longer rise time is due to slow nonradiative relaxation from a charge transfer state (CTS) to the ${ }^{2} F_{5 / 2}$ level. In $\mathrm{Yb}^{3+}$-doped YAG, the charge transfer absorption and the charge transfer luminescence have been reported. ${ }^{20-23} \mathrm{In}$ addition, it had been known that the emission of $\mathrm{Ce}^{3+}$ was quenched by the process of charge transfer state $\left(\mathrm{Ce}^{4+}-\mathrm{Yb}^{2+}\right)$ in $\mathrm{Ce}^{3+}$-doped crystal that consists of $\mathrm{Yb}$, such as $\mathrm{LiYbF}_{4},{ }^{24} \mathrm{YbSiO}_{5} \cdot{ }^{25,26}$ That is because the $\mathrm{Ce}^{3+}$ and $\mathrm{Yb}^{3+}$ changes to $\mathrm{Ce}^{4+}$ and $\mathrm{Yb}^{2+}$ easily. In a similar system, it was reported that $\mathrm{Yb}^{3+} \mathrm{IR}$ emission in $\mathrm{Tb}^{3+}-\mathrm{Yb}^{3+}$ codoped $\mathrm{Y}_{2} \mathrm{O}_{3}$ by UV excitation was caused through $\mathrm{Tb}^{4+}-\mathrm{Yb}^{2+}$ charge transfer state. ${ }^{12}$ Therefore, it is considered that the energy transfer from $\mathrm{Ce}^{3+}$ to $\mathrm{Yb}^{3+}$ may be caused through a CTS $\mathrm{Ce}^{4+}-\mathrm{Yb}^{2+}$ (Fig. 13).

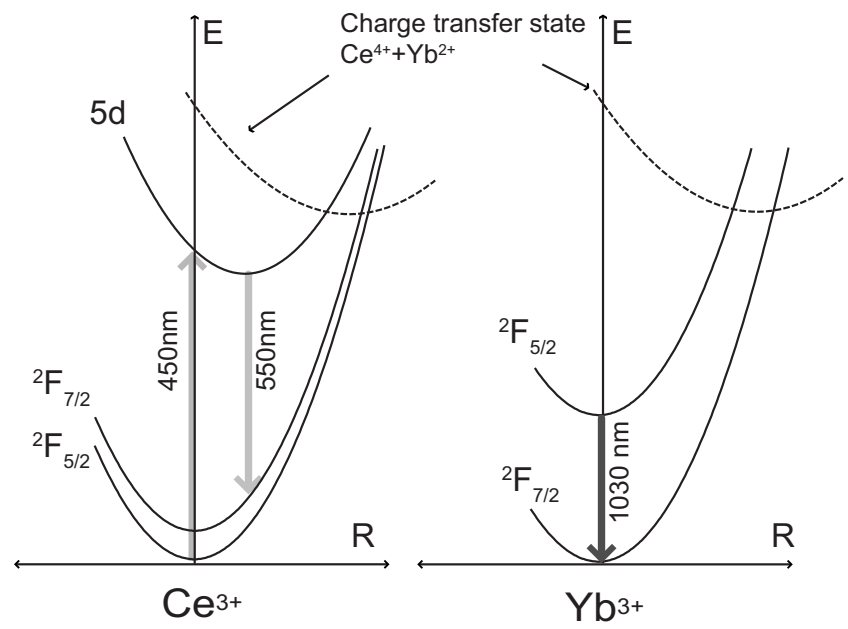

FIG. 13. Configuration coordinate model of emission and energy transfer from $\mathrm{Ce}^{3+}$ to $\mathrm{Yb}^{3+}$. Dashed lines are $\mathrm{Ce}^{4+}-\mathrm{Yb}^{2+}$ charge transfer state.

\section{CONCLUSION}

The energy transfer from $\mathrm{Ce}^{3+}$ and sensitized luminescence of $\mathrm{Yb}^{3+}$ in polycrystalline YAG ceramics was observed. The quantum yields of $\mathrm{Yb}^{3+}$ emission upon $\mathrm{Ce}^{3+}: 5 d$ level excitation were lower than that value expected for the ideal quantum cutting mechanism. In addition the relaxation time, which was estimated from measurement of $\mathrm{Yb}^{3+}$ decay curve by $440 \mathrm{~nm} \mathrm{LD}$ excitation, from $5 d$ levels of $\mathrm{Ce}^{3+}$ to ${ }^{2} F_{7 / 2}$ of $\mathrm{Yb}^{3+}$ was not consistent to the lifetime of $\mathrm{Ce}^{3+}$ estimated from measurement of $\mathrm{Ce}^{3+}$ decay curve by $440 \mathrm{~nm} \mathrm{LD}$ excitation. From the QY of $\mathrm{Yb}^{3+}$ emission by $935 \mathrm{~nm}$ excitation, the concentration quenching did not occur until $x$ $=0.5 \mathrm{Yb}^{3+}$ concentration. Therefore, we indicated that the energy transfer from $\mathrm{Ce}^{3+}$ to $\mathrm{Yb}^{3+}$ in $\mathrm{YAG}$ was not direct process and has some nonradiative processes that were not the concentration quenching $\mathrm{Yb}^{3+}$.

\section{ACKNOWLEDGMENTS}

These investigations were supported by the Toray Science Foundations and the Nippon Sheet Glass Foundation for Materials Science and Engineering.

${ }^{1}$ W. G. J. H. M. van Sark, A. Meijerink, R. E. I. Schropp, J. A. M. van Roosmalen, and E. H. Lysen, Sol. Energy Mater. Sol. Cells 87, 395 (2005).

${ }^{2}$ W. Shockley and H. J. Queisser, J. Appl. Phys. 32, 510 (1961).

${ }^{3}$ T. Trupke, M. A. Green, and P. Wurfel, J. Appl. Phys. 92, 1668 (2002).

${ }^{4}$ D. L. Dexter, Phys. Rev. 108, 630 (1957).

${ }^{5}$ W. W. Piper, J. A. DeLuca, and F. S. Ham, J. Lumin. 8, 344 (1974).

${ }^{6}$ J. L. Sommerdijk, A. Bril, and A. W. de Jager, J. Lumin. 8, 341 (1974).

${ }^{7}$ R. T. Wegh, H. Donker, A. Meijerink, R. J. Lamminmäki, and J. Hölsä, Phys. Rev. B 56, 13841 (1997).

${ }^{8}$ R. T. Wegh, H. Donker, K. D. Oskam, and A. Meijerink, Science 283, 663 (1999).

${ }^{9}$ R. T. Wegh, E. V. D. Van Loef, and A. Meijerink, J. Lumin. 90, 111 (2000).

${ }^{10}$ W. Stręk, A. Bednarkiewicz, and P. J. Dereń, J. Lumin. 92, 229 (2001).

${ }^{11}$ P. Vergeer, T. J. H. Vlugt, M. H. F. Kox, M. I. den Hertog, J. P. J. M. van der Herden, and A. Meijerink, Phys. Rev. B 71, 014119 (2005).

${ }^{12}$ S. Ye, B. Zhu, J. Chen, J. Luo, and J. R. Qiu, Appl. Phys. Lett. 92, 141112 (2008).

${ }^{13}$ J. L. Yuan, X. Y. Zeng, J. T. Zhao, Z. J. Zhang, H. H. Chen, and X. X. Yang, J. Phys. D: Appl. Phys. 41, 105406 (2008).

${ }^{14}$ Q. Y. Zhang, G. F. Yang, and Z. H. Jiang, Appl. Phys. Lett. 91, 051903 (2007).

${ }^{15}$ X. Liu, Y. Qiao, G. Dong, S. Ye, B. Zhu, G. Lakshminarayana, D. Chen, and J. Qiu, Opt. Lett. 33, 2858 (2008).

${ }^{16}$ Y. Narukawa, I. Niki, K. Izuno, M. Yamada, Y. Murazaki, and T. Mukai, Jpn. J. Appl. Phys., Part 241 L371 (2002).

${ }^{17}$ S. Fujita, A. Sakamoto, and S. Tanabe, IEEE J. Sel. Top. Quantum Electron. 14, 1387 (2008).

${ }^{18}$ JCPDS PDF No. 33-0040.

${ }^{19}$ JCPDS PDF No. 23-1476.

${ }^{20}$ L. van Pieterson, M. Heeroma, E. de Heer, and A. Meijerink, J. Lumin. 91, 177 (2000).

${ }^{21}$ N. Guerassimova, N. Garnier, C. Dujardin, A. G. Petrosyan, and C. Pedrini, Chem. Phys. Lett. 339, 197 (2001).

${ }^{22}$ M. Nikl, A. Yoshikawa, and T. Fukuda, Opt. Mater. (Amsterdam, Neth.) 26, 545 (2004).

${ }^{23}$ I. Kamenskikh, C. Dujardin, N. Garnier, N. Guerassimova, G. Ledoux, V. Mikhailin, C. Pedrini, A. Petrosyan, and A. Vasil'ev, J. Phys.: Condens. Matter 17, 5587 (2005).

${ }^{24}$ J. W. M. Verweij, C. Pédrini, D. Bouttet, C. Dujardin, H. Lautesse, and B. Moine, Opt. Mater. (Amsterdam, Neth.) 4, 575 (1995).

${ }^{25}$ D. W. Cooke, R. E. Muenchausen, B. L. Bennett, K. J. McClellan, and A. M. Portis, J. Lumin. 79, 185 (1998).

${ }^{26}$ J. F. Rivas-Silva, S. Durand-Niconoff, T. M. Schmidt, and M. Berrondo, Int. J. Quantum Chem. 79, 198 (2000). 